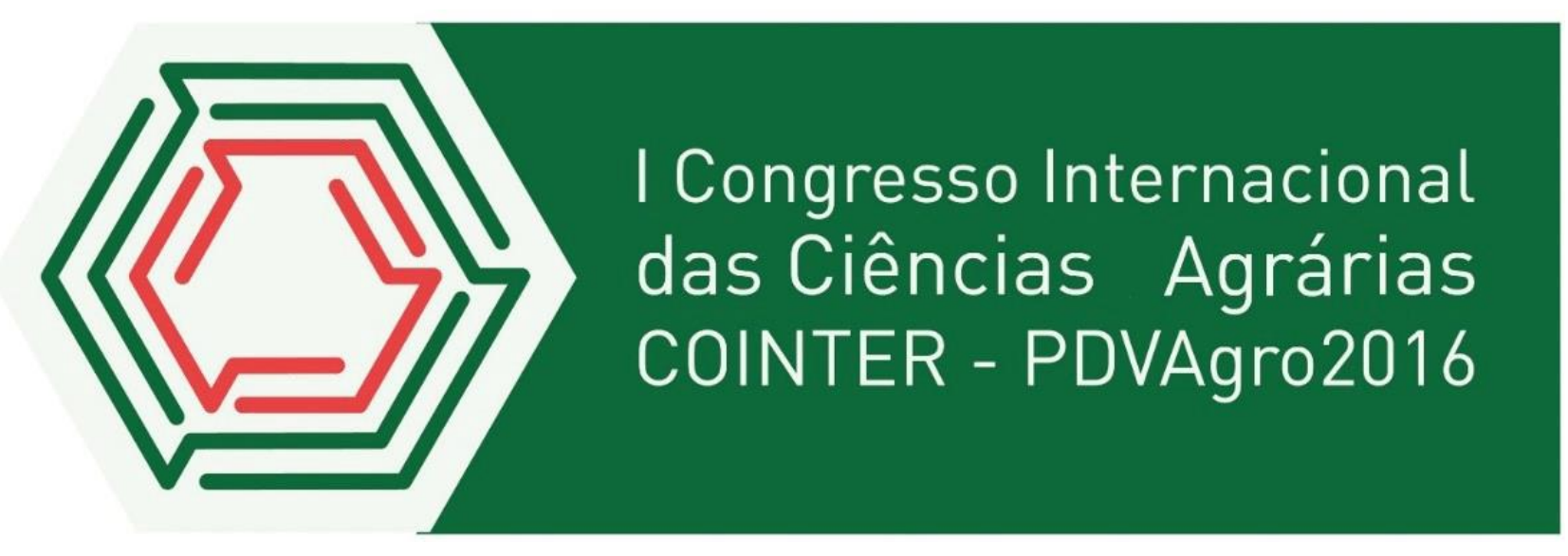

\title{
SÍTIO AGROECOLÓGICO DA COMUNIDADE DO SALGADO EM CASSERENGUE-PB COMO UM "LABORATÓRIO VIVO" PARA A EDUCAÇÃO PARA CONVIVÊNCIA COM O SEMIÁRIDO
}

\author{
Apresentação: Relato de Experiência \\ Rayana Vanessa Alves Silva ${ }^{1}$; Marcilene Santos Silva²; Regivaldo Henrique da Silva ${ }^{3}$; \\ Dalvilene Macena da Silva ${ }^{4}$ Alexandre Eduardo de Araújo ${ }^{5}$
}

\section{Introdução}

A experiência consistiu em um processo prático reflexivo de educação para convivência com o Semiárido. Esta experiência ocorreu no contexto de uma comunidade rural tradicional com o grupo infanto-juvenil "Sementes do Futuro" de filhos (as) de agricultores (as) familiares campesinos no município de Casserengue- PB, o qual está inserido na área geográfica de abrangência do semiárido brasileiro.

\section{Relato de Experiência}

Historicamente, o valor da agricultura familiar sempre foi negado, onde os sujeitos do campo, vem desde muito tempo enfrentando obstáculos para se manterem atuantes em seus espaços, seja pela falta de políticas para o campo familiar, seja pelo não reconhecimento de suas potencialidades, desencadeando assim uma desvalorização de suas lutas e dinâmicas, o que consequentemente vem atrelado aos modelos educacionais implementados nestes espaços, que negam a cultura e identidade destes sujeitos, contribuindo cada vez mais para o aumento desta problemática. Apesar do desafio já mencionado, a Agricultura Familiar desenvolvida no Semiárido Brasileiro tem como um dos principais desafios assegurar a convivência harmônica com as

\footnotetext{
1Pós-graduação em Ciências Agrárias “Agroecologia”, UFPB/CCHSA, rayana.vanessa@hotmail.com

${ }^{2}$ Graduação em Licenciatura em Ciências Agrárias, UFPB/CCHSA, marcilene-1995@hotmail.com

${ }^{3}$ Técnico em Aquicultura, CAVN/UFPB, regivaldohenrique@hotmail.com

${ }^{4}$ Graduação em Licenciatura em Pedagogia, UFPB/CCHSA, dalvilenemacena@ hotmail.com

${ }^{5}$ Docente, UFPB/CCHSA, alexandreeduardodearaujo@hotmail.com
} 
condições edafoclimáticas, cuja maior finalidade é a continuidade dos processos produtivos, possibilitando trabalho, geração de renda, segurança alimentar e reduzindo a degradação ambiental. A irregularidade na distribuição espaço-temporal das chuvas ainda é um ambiente pouco compreendido nos processos produtivos pouco adaptados (SILVA, E. J. L, 2013; SILVA, R. H, 2013).

A experiência foi realizada por meio do projeto de extensão- Escola Agroecológica, a atividade consistiu na realização de uma travessia com o grupo infanto-juvenil "Sementes do Futuro" pelo sítio agroecológico da comunidade tradicional do Salgado em Casserengue-PB. A metodologia utilizada partiu de uma pesquisa ação participante fundamentada na educação para convivência com o Semiárido em um ambiente não escolar.

A travessia foi realizada com o objetivo de conhecimento detalhado sob diferente abordagem da realidade do sítio agroecológico, onde o agricultor Regivaldo, elaborou e apresentou o mapa do sítio e em seguida junto ao grupo realizou uma travessia, visitando cada área: a plantação de palma, de algodão, realizando a colheita do mesmo, barragem subterrânea, a horta, onde colheram a alface, tanque de pedra e o lajeiro (figura 1).
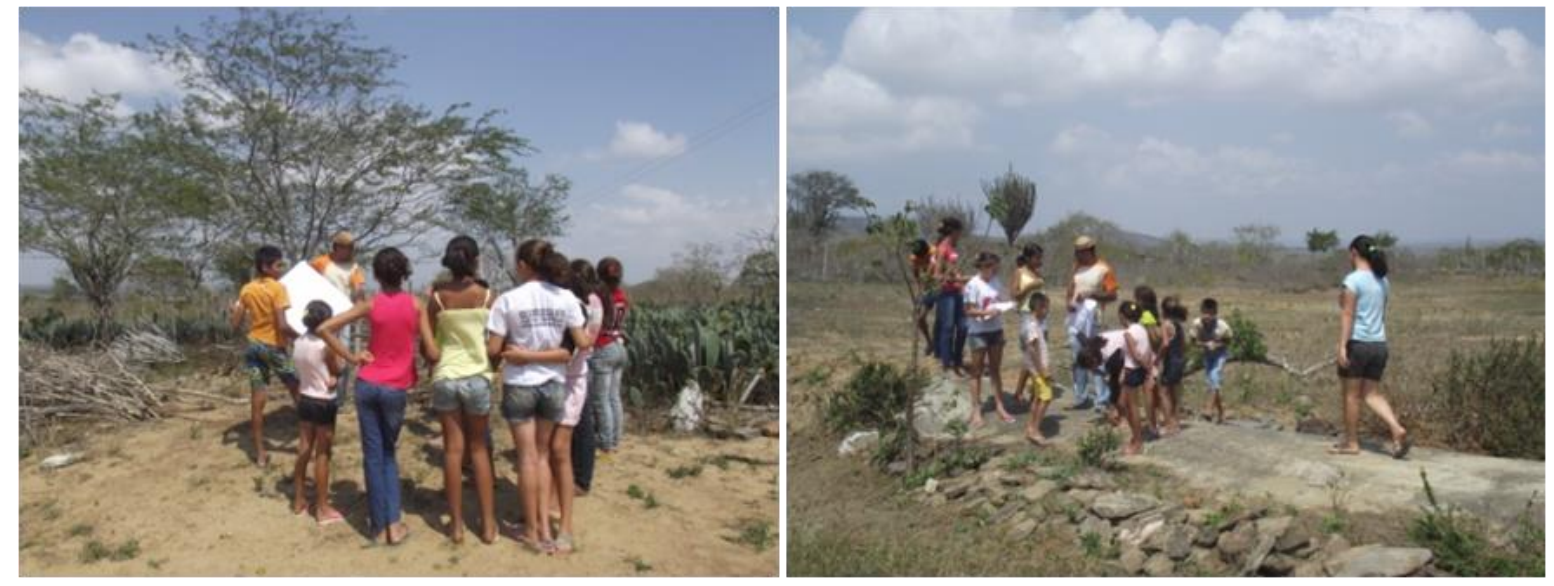

Figura 1: Travessia realizada no sítio agroecológico pelo grupo infanto-juvenil. Fonte: própria

\section{Considerações}

A travessia realizada pelo grupo serviu como um relevante subsídio didático-pedagógico e um laboratório vivo capaz de despertar a sensibilização para a questão da convivência com o semiárido, a valorização dos saberes do agricultor pelo grupo e da ressignificação da identidade destes sujeitos.

\section{Referências}


SILVA, E. J. L. da; DIAS, A. D. L.; SILVA, D. M. da; LIMA, G. A. de; FERREIRA, M. J. O.; SILVA, R. V. A. Relato de Experiência com Educandos da Educação Escolar do Campo. In: SILVA, Eduardo...[et al.], (Org.). Educação do Campo: Relatos de Experiência. João Pessoa: Editora da UFPB, 2013. p. 126-150.

SILVA, R. H.; SILVA, R. V. A.; FERREIRA, J. G. H.; ARAÚJO, A. E. de.; BARBOSA, A. S. CONVIVÊNCIA COM O SEMIÁRIDO BRASILEIRO: SOCIALIZANDO CONHECIMENTOS A PARTIR DA COMUNIDADE SALGADO DO BOLA. XIV Encontro 